\title{
Informationalized Teaching Design Promotes Effective Teaching of Theoretical Courses: Take "Clinical Diagnosis Technology" Course in Higher Vocational School as an Example
}

\author{
Qianwen $\mathrm{Li}^{1}$, a and Xuegang Zhang ${ }^{1, b^{*}}$ \\ ${ }^{1}$ Guangdong food and drug vocational college, GuangZhou, China \\ aliqianwen@gdyzy.edu.cn, bzhangxg@gdyzy.edu.cn
}

\begin{abstract}
Keywords: Effective Teaching; Informationalized Teaching Design; Theoretical Course; Higher Vocational School; Diagnosis Course
\end{abstract}

\begin{abstract}
Effective teaching" theory refers to an innovative teaching theory that is based on teachers and affects students' learning ability through teachers' teaching behavior, which has higher requirement in the speed, effectiveness and efficiency of knowledge dissemination that is hard to be meet by the traditional teaching method. The advantages of informational technology such as high speed, high efficiency, intuition, vividness and other advantages can just solve these bottleneck problems smoothly. Introducing informational technique into teaching design ensures that teaching truly reach the requirement of "effectiveness". This article takes the informationalized teaching design of Clinical Diagnosis Technology for rehabilitation technique specialty in higher vocational school as an example to discuss how to use the informationalized teaching design to promote the effective teaching of theoretical courses in higher vocational schools.
\end{abstract}

\section{Preface}

"Effective teaching" theory refers to an innovative teaching theory that is based on teachers and affects students' learning ability through teachers' teaching behavior ${ }^{[1]}$. Since the concept of "effective teaching" attracted pubic attention in domestic areas in the late 1990s, it has been heated discussed for 20 years and has also produced a large number of theoretical and practical research results ${ }^{[2]}$.

The concept of effective teaching requires the teaching content to be effective (Effective amount of knowledge ), homework and exercises to be effective, and effective evaluation methods to be used in evaluating students ${ }^{[3]}$. However, in the traditional teaching activities of theoretical courses, teachers mainly impart knowledge through explanation and taking examples. Under the background of the enrollment expansion of colleges, the students in higher vocational schools are not so well developed in thinking ability that teaching is really hard to achieve " effectiveness".

In recent years, informationalized technology has been developing rapidly. Its special advantages such as high speed, high efficiency, intuition, vividness and so on ${ }^{[4]}$ can, break through the limitation of time and space and the difficulty of language description, vividly display materials so that the students could acquire expertise through visualization teaching ${ }^{[5]}$. Moreover, since internet-based informational technology is highly efficient in communication, the application of which in teaching can make it easier for students to understand and master what they have learned in class, effectively stimulate students' enthusiasm for learning and thinking, enhance students' level of information technology. What's more, the spirit of cooperative learning can be stimulated among students, and their abilities of analyzing and solving problems can also be escalated a lot ${ }^{[6]}$.

Therefore, it has been made much emphasis on the great role that informationalized teaching played in the process of teaching. Chapter 19 of the National Medium and Long-Term Educational Reform and Development Plan (2010 - 2020) clearly states that it is bound to " speed up the educational informationalizing process", "strengthen the development and application of high-quality educational resources" and " strengthen the application of information technology ${ }^{[7]}$.

However, the current informationalized construction in higher vocational colleges is mainly focused on the construction of various virtual training rooms to solve the problem of limited 
training venues and conditions. However, the great role that the application of informationalized teaching in theoretical teaching has not been fully exerted.

This article mainly takes the informationalized teaching design of Clinical Diagnosis Technology for rehabilitation technique specialty in higher vocational schools as an example so as to discusse how to use which to promote the effective teaching of theoretical courses in higher vocational schools.

\section{Analysis of Teaching Needs}

"Clinical Diagnosis Technology" is a specialized basic course of rehabilitation technique specialty in our school, which connects basic medicine to clinical medicine and establish the diagnostic thinking. The establishment of diagnostic thinking is vitally important for students' study of follow-up courses in rehabilitation major and for taking up their jobs in the future. Therefore, how to effectively enable the students to learn abstract theoretical knowledge so as to better establish their clinical diagnostic thinking has become the most urgent problem to be solved in the teaching design of this course.

The main teaching objects of this course are students who major in rehabilitation therapy in higher vocational school. After graduation, the major job positions most students will take are rehabilitation therapists in the hospital. In the background of enrollment expansion in colleges and universities, many students in higher vocational schools are emotional in learning, who have no enthusiasm for learning theoretical knowledge, and lack abstract thinking ability while have strong imaginal thinking. At the same time, most of the students are highly rely on intelligent devices and networks in their daily life.

Based on the analysis of the teaching objects, the curriculum group introduced the informationalized teaching concept and technology into the teaching design.

In order to improve students' enthusiasm for learning theoretical knowledge, we used a large number of network cases, videos and other materials to arouse their interest, and used some current affairs cases to ensure that students would be able to feel that theoretical knowledge and life are interconnected. For example, we led in some of the classes with video clips of TV series sections of "House" to show the medical diagnosis process, and we used clinical diagnosis cases published by medical self-media on Micro-blog to show the charm of diagnostics.

Targeted to students' lack of thinking ability, our solution was, with the help of visualized animation approaches and analogical teaching, to transform boring concept into visualized knowledge. For example, in lesson "Formation Mechanism and Diagnosis of Jaundice", we creatively drew an analogy of the metabolic process of bilirubin to a production and sales chain of products and made vivid animation to visualize abstract theories to help students understand the theoretical knowledge.

Based on the students' habits of using mobile phones and internet in their daily life, we made students' extracurricular learning activities on line so as to connected them closer with students' daily life. Accordingly, we used the informationalized teaching platform "Moso Teach" to share the learning materials, post homework and tests, communicate with students in real time, which can not only manage students' learning behavior, but also give students timely learning feedback to improve their learning efficiency.

\section{Teaching Design and Implementation}

The course content of " Clinical Diagnosis Technology" is mainly divided into three modules, namely " Symptomatology", " Physical Examination" and " Experimental Diagnosis". The contents of the three modules are different from each other and so are the teaching emphases. This article mainly took the "Symptomatology" module as an example. The "Symptomatology" module focuses on the connection between pathological mechanism and clinical manifestations, which is mainly theoretical and requires students to connect basic medical contents such as physiology and pathology while learning it. We divided teaching process into three parts , namely pre-class, 
while-class (warm-up, difficulties and emphasis) and post-class according to the teaching time sequence and applied informationalized technology to the teaching process.

\section{Review post before class}

In the symptomatology module, the content of each lesson needs to build up horizontal links with basic clinical courses. In order to help students' reviewing, teachers sent the materials of relevant knowledge points to each student through "Moso Teach" two days before the classes, and issued some small test questions about the preview content. According to the students' test results, teachers in charge of the lesson could have grasped the students' mastery extent of the former knowledge and properly adjusted the teaching methods in a timely manner.

\section{Scene led in to start class}

At the beginning of each lessen, we commonly led in with pictures, videos and cases.

In order to assure the scene led in more interesting and vivid and have students exerted interest in learning the content of the course, we made full use of internet resources to ensure timeliness and interest of materials when selecting materials. For example, in the lesson of "Chest Pain", we used the description made by Yu Ying, a doctor from the Emergency Department of Xiehe Hospital, about a patient's symptom of myocardial infarction to naturally introduce the topic and fully convey the experience of clinical frontline work. Take another example, in " Jaundice" section, we used a scene from TV series "House" to introduce symptom of jaundice (Figure 1), so that students can have an intuitive impression on the concrete symptom of " jaundice" without real patients.

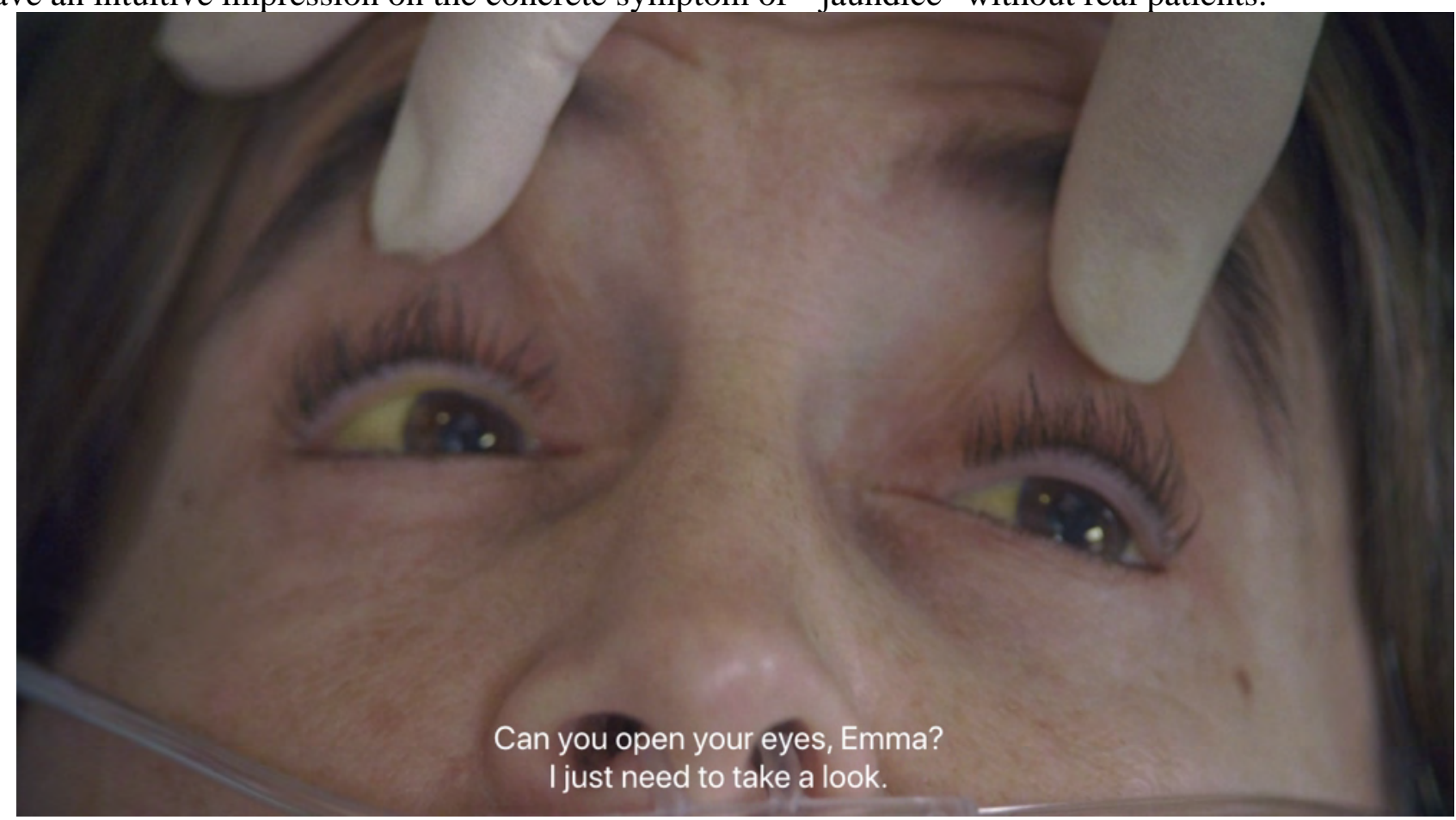

Figure 1. Symptom of jaundice patient in the TV series "House"

\section{Difficulties overcome while class}

The difficulty of the symptomatology is to understand the different pathological mechanisms causing the symptoms and the different clinical manifestations. The common feature in those theoretical knowledge is abstraction.

The intuitive and vivid feature of informationalized technology have unique advantages in the visualization of abstract information. The techniques that have been commonly used include pattern diagrams, animations, virtual simulations and etc. We usually use the first two in the teaching of pathological mechanism theory. For example, when we explained the pathological mechanism of hepatic edema, the mode diagram well showed the interaction among different fluid metabolic pathways (Figure 2). In addition to the traditional animation and pattern display, we also creatively combined animation with analogy teaching to make the pathological mechanism easier to be 
understood and mastered. For example, in the explanation of the pathological mechanism of jaundice, we used animation to show the analogy teaching method, which analogizes the metabolic pathway of bilirubin into a production and sales pathway of leather shoes (Figure 3). Unconjugated bilirubin is like raw materials supplied by raw material suppliers, the liver is like a factory producing leather shoes, and conjugated bilirubin is the leather shoe produced. Leather shoes are sold downstream, and some are recalled due to quality problems. In this way, the obstacles appearing in every link of the production and sales route correspond to the dysfunction in every link of bilirubin metabolism, which explains the pathological mechanism of jaundice formation.

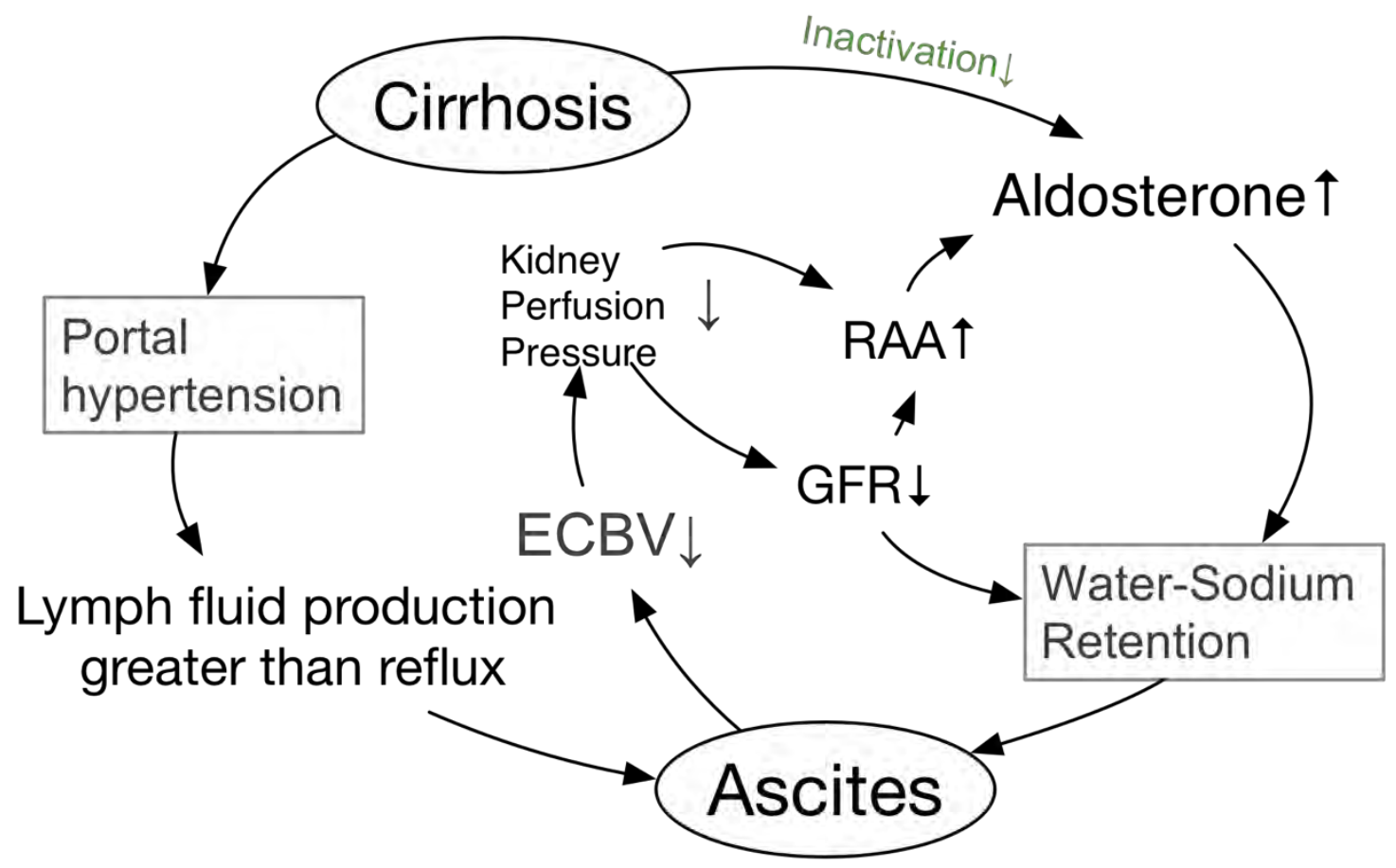

Figure 2. Pattern of Pathological Mechanism of Hepatogenic Edema

\section{2、 Hemolytic Jaundice}



BACK $\bigcirc$ REPLAY ONEXT

Figure 3 . Compare bilirubin metabolism to production lines 


\section{Emphases solved by task-driven method}

The emphasis of the symptomatology module is differential diagnosis of various clinical manifestations. It requires the students, after overcome the difficult points, can fully understand the different characteristics of a certain symptom in different pathological mechanisms, and then distinguish them clearly so as to establish clinical diagnostic thinking abilities in their analysis and considerations.

Consequently, we adopted the task-driven method, formed the emphasis content into tasks of typical case discussion through the Moso Teach. After students comprehended difficult contents, teacher released relevant cases and corresponding questions on the activity platform of the Moso Teach. Students freely discussed in groups and experience the process of diagnosis, and answers was uploaded to the activity platform in units of groups afterwards. Teachers commented and graded immediately on the activity platform, so that the participation of each student could be successfully recorded.

\section{Memory consolidated after class}

After class, in order to consolidate students' memory of the lesson, teachers arranged homework. In the teaching design of this course, homework was done through the homework platform of Moso Teach, which includes multiple choice questions and subjective questions. To examine specific knowledge points, homework was in the form of multiple choice questions, which was scored by the platform automatically, while to examine knowledge contact ability, the homework was in the form of subjective questions, which was scored by the teacher manually.

In addition, to strengthen the communication between teachers and students, we also used the Q\&A function of the Moso Teach, which enabled both students and teachers to communicate directly and conveniently. Students also had special space to discuss their studies and even answer each other's questions, which promoting the learning atmosphere a lot.

\section{Evaluation of Teaching Effect}

Our school started to recruit students majoring in rehabilitation technology in September 2013, opened the course of " Clinical Diagnosis Technology" in 2014, and started the informationalized teaching reform of this course in 2015. Judging from the results of the course examination (Figure 4), the passing rate and outstanding rate of students have obviously increased from 2014 to 2017 , laid a solid foundation for future study and clinical work.

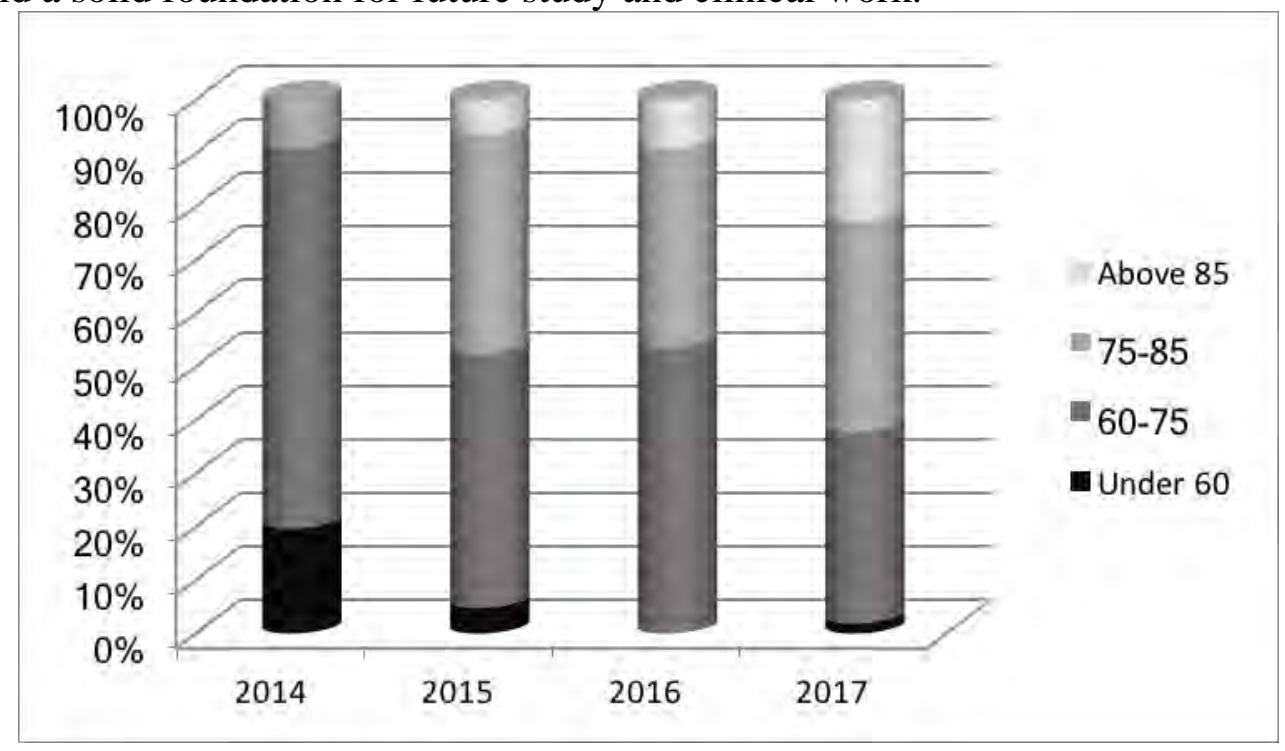

Figure 4. The proportion of students in each score segment (recent four years)

Since the introduction of information technology into teaching in this course group, students' understanding of theoretical knowledge has obviously improved compared with previous students. 
They could better carry out preliminary diagnosis and analysis of typical cases and preliminarily establish the thinking ability of clinical diagnosis.

The author summarized and sorted out the teaching reform experience of this course, participated in the 2017 Guangdong Province Higher Vocational Informationalized teaching competition and won the first prize in the end, reflecting that society and superior experts have highly recognition towards informationalized teaching reform of our school.

\section{Discussion and Summary}

Effective teaching is a practical activity in which teachers and students should follow the objective law of teaching activities and promote students' integration, coordination and sustainable progress and development in "Three-dimensional Goals", namely knowledge and skills, processes and methods, emotions, attitudes and sense of worth with optimal speed, efficiency and effectiveness ${ }^{[3]}$. The core connotation of effective teaching mainly lies in the high-speed, high-efficiency and effectiveness of knowledge dissemination. The development of informationalized technology based on internet+ precisely meets the requirements of effective teaching and becomes an advantageous tool for effective teaching in the teaching activities in the new era.

The visualization of informational technology is a powerful tool to transform theoretical knowledge into effective knowledge

Effective teaching firstly requires that the knowledge in teaching should be effective, which emphasizes the effective absorption of students without blindly pour in the knowledge. However, the theoretical knowledge of symptomatology is precisely the difficulty for students to absorb effectively in the traditional medical teaching mode because of its high requirement for abstraction and transfer ability. Under the background of the current enrollment expansion in colleges and universities, the training of students majoring in rehabilitation therapy in higher vocational school is in line with the needs of employment positions, yet there is a certain gap between them and the ability of undergraduate students. Thus, teaching in the traditional way is bound to cause great defects in students' diagnostic thinking ability and leave hidden dangers for clinical work in the future.

Owing to the support of information technology, we led in the courses with video clips to arouse students' interest and create presupposition of knowledge, or used mechanism diagram and animation to visualize abstract knowledge and reduce the difficulty of knowledge absorption. And with the rapid development of information technology, we will also introduce clinical situations into the classroom through mature VR and AR technology so that students can experience immersion and visualize abstract knowledge. In short, through informationalized technology, theoretical knowledge can be easily converted into effective knowledge.

The high speed and efficiency of informational technology ensures the effectiveness of homework and exercises

Whether in or out of class, homework and exercises are important links and organic components of teaching, which are important ways for students to acquire, consolidate and apply knowledge, improve their quality and cultivate their emotional attitudes.

In the traditional teaching mode, teachers should not only carefully design homework and exercises to ensure that students can achieve the goal of training in the shortest time, but also spend a lot of time correcting homework to complete the feedback function of homework in order to ensure the effectiveness of homework and exercises. The correction speed should be fast enough to ensure the timeliness of feedback. However, the characteristics of professional learning of college students determine that the content load of homework should be sufficient, and it is often done by checking materials or asking students to have discussions in groups. This kind of task load determines that the time spent in homework cannot be too short. If the teacher comments on a report in class, the teaching time is not enough to get better teaching feedback. Here, there is a contradiction being triggered between the workload and both the quality and timeliness of teaching feedback. 
According to the requirement of effective teaching, homework and exercises must be carefully designed to ensure their effectiveness. In addition, teachers have to spend a lot of time to correct the assignments to complete the feedback function of the assignments. At the same time, the grading speed must be fast enough to guarantee the feedback timeliness.

In the informationalzied teaching based on the informationalized teaching platform, carefully designed homework is released through the teaching platform, on which students can complete tasks within the time limit by taking groups as units as soon as they receive the posted information. During this time limit, students are free and totally independent. As Marx said: " free time, the time at your disposal is wealth itself. "[8] After completing the task, assignments are submitted to the platform by group. Depending on the arrangement of teaching time, teachers can choose some of the assignments to discuss in class or provide feedback in the teaching platform. In addition to obtaining homework results, each student within the group can see the teacher's feedback and communicate with the teacher directly, one-to-one or many-to-one, and even many-to-many. The contradiction between teaching feedback and homework load has been solved well.

\section{Informationalized technology also innovates the evaluation method and improve its effectivity}

The traditional teaching evaluation is based on summative evaluation, mainly based on homework results and test scores, which is one - sided. But effective teaching, apart from teaching specific and repeated facts and formulas, involves the cultivation of lifelong learning habits and the establishment of professional qualities. For example, the course " Clinical Diagnostic Technology" emphasizes very much on helping students to establish diagnostic thinking and to cultivate the ability of humanistic care for clinical work, which were difficult to accomplish through traditional teaching evaluation methods.

Thus, when we uses the informationalized teaching platform as a carrier of teaching, every learning behavior of students has left a record on the platform, including some learning habits such as receiving or reading materials, previewing before class, reviewing after class and so on, or the brainstorming spark comes from intense discussions, or even the confusion occur in one-to-one communication with teachers. All those learning behaviors are all recorded and become part of students' final result, which accomplished process assessment and improved students' sense of achievement and confidence in learning.

In summary, informational technology is a powerful tool to achieve effective teaching, especially in teaching theoretical courses in higher vocational schools.

\section{Acknowledgements}

The authors and their work were Supported by:

Natural Science Fund Project of Guangdong Food and Drug Vocational College (Research and Realization of Informatization Practical Training System of Music Therapy Technology), grant no.: 2015 YZ008.

Guangdong Higher Vocational Education Medical and Health Professional Teaching Steering Committee Teaching Reform Research Project Approval Topic, grant no.: 2015008.

Education Research Fund Project of Guangdong Food and Drug Vocational College, grant no.: $201015 Y 1512$.

\section{Reference}

[1] F. Feng: China's Adult Education, Vol. 19 (2014) No.3, p142. (In Chinese)

[2] SJ. Lu: Journal of Northwest Normal University ( Social Science Edition ), vol. 46(2009) No.5, p113. (In Chinese)

[3] QQ. Song: The Concept and Implementation Strategy of Effective Teaching (Zhejiang University Press, China 2007)p.178 (In Chinese)

[4] SZ. Pang and XL. Gao: Medical Theory and Practice, Vol. 31 (2018) No.8, p1240. (In Chinese) 
[5] HY. Li: Research on the Application of Information Technology in the Teaching of Specialized Theoretical Courses in Secondary Vocational Schools (MS., Beijing Institude of Technology, China 2015), p.18.

[6] YC. Zhang and YX. Wang: Vocational and Technical Education, Vol. 36 (2015) No.36, p70. (In Chinese)

[7] CB. Xie, XJ. Hou, and SG. Zhang: China's Distance Education, Vol. 16 (2014) No.12, p84. (In Chinese).

[8] Marx and Engels: Complete Works of Marx and Engels (People's Publishing House, China 2016)p.532 